\title{
ACESSIBILIDADE DIGITAL E O MUNDO REAL: UMA ANÁLISE SOBRE AUDIOGUIA DO MUSEU DO AMANHÃ
}

\section{DIGITAL ACCESSIBILITY AND THE REAL WORLD: AN AUDIOGUIA ANALYSIS OF “MUSEU DO AMANHÃ}

\author{
Luciana Tavares Perdigão ${ }^{1}$, Esp. \\ Neuza Rejane Wille Lima², PhD. \\ (1) Fundação Cecierj e Universidade Federal Fluminense (Instituição) \\ e-mail: lucianaperdigao@id.uff.br \\ (2) Universidade Federal Fluminense \\ e-mail: $\underline{\text { rejane_lima@id.uff.br }}$
}

audioguia; tecnologia assistiva; áudio-descrição

O presente estudo aponta um relato de experiência de uma visita realizada no Museu do Amanhã por dois estudantes do Curso de Mestrado Profissional em Diversidade e Inclusão da Universidade Federal Fluminense (CMPDI UFF), sendo um deles cego. Ambos utilizaram o audioguia para visitar a exposição principal do museu. O objetivo foi analisar a acessibilidade do conteúdo apresentado nesse dispositivo e fazer um paralelo da experiência de uma pessoa com visão e a pessoa cega. A análise foi baseada nas pesquisas sobre tecnologia assistiva de SARTORETTO \& BERSCH (2013) à luz dos estudos sobre áudio-descrição de LIMA (2011) e MOTTA (2016).

Audioguide; Assistive technology; Audio description

This study presents an experience report of a visit at the Museum of Tomorrow by two students of the Professional Master's Degree in Diversity and Inclusion of the Federal Fluminense University (CMPDI - UFF), one of them blind. Both used the audioguide to visit the main exhibit of the museum. The goal was to analyze the accessibility of the content presented in this device and to parallel the experience of a person with vision and the blind person. The analysis was based on SARTORETTO \& BERSCH (2013) assistive technology research under the guidance of LIMA (2011) and MOTTA (2016) audiodescription studies.

\section{Introdução}

O Museu do Amanhã é uma iniciativa da Prefeitura do Rio com projeto do arquiteto espanhol Santiago Calatrava. Tem a acessibilidade como premissa da construção física do prédio e, principalmente, da relação entre a equipe do Museu e seus visitantes. (RIO DE JANEIRO, 2015). O presente estudo aponta um relato de experiência de uma visita realizada no Museu do Amanhã por dois estudantes do Curso de Mestrado Profissional em Diversidade e Inclusão da Universidade Federal Fluminense (CMPDI - UFF), sendo um deles cego. Ambos 


\section{$16^{\circ}$ \\ ERGODESIGN USIHC CINAHPA}

utilizaram o audioguia para visitar a exposição principal do museu. $\mathrm{O}$ objetivo foi analisar a acessibilidade do conteúdo apresentado nesse dispositivo e fazer um paralelo da experiência de uma pessoa com visão e a pessoa cega.

\section{Museu inclusivo?}

Embora o debate sobre o denominado Museu Inclusivo já esteja em foco no campo da Museologia, [...] existe um hiato entre o discurso e a prática da inclusão. (BERQUÓ, 2011). Entendese por inclusão "um processo bilateral no qual as pessoas, ainda excluídas, e a sociedade buscam, em parceria, equacionar problemas, decidir sobre soluções e efetivar a equiparação de oportunidade para todos." (SASSAKI apud BERQUÓ, 2011)

Pessoas cegas e com baixa visão também podem ser consumidoras de cultura, desde que sejam respeitadas em seus direitos de acessibilidade comunicacional. (MOTTA, 2016). Segundo Motta, o número de pessoas com deficiência visual que participam de museus vem aumentando significativamente. A áudio-descrição é uma das tecnologias assistivas responsáveis por esse movimento de inclusão cultural. De acordo com Sartoretto \& Bersch (2013), tecnologia assistiva é um termo ainda novo, utilizado para identificar todo o arsenal de Recursos e Serviços que contribuem para proporcionar ou ampliar habilidades funcionais de pessoas com deficiência e consequentemente promover vida independente e inclusão.

Sobre a áudio-descrição podemos entender que

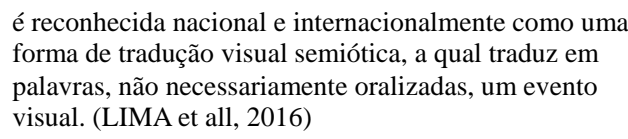

Para disponibilizar a áudio-descrição aos visitantes de um museu, são utilizados os audioguias que são sistemas sonoros oferecidos via aplicativos móveis ou via dispositivos cedidos pela própria instituição.

Um audioguia servirá igualmente para um visitante normovisual, podendo ser ainda transformado numa mais valia ao $16^{\circ}$ Ergodesign - Congresso Internacional de Ergonomia e Usabilidade de Interfaces Humano Tecnológica: Produto, Informações Ambientes Construídos e Transporte

$16^{\circ}$ USIHC - Congresso Internacional de Ergonomia e Usabilidade de Interfaces Humano Computador

CINAHPA | 2017 - Congresso Internacional de Ambientes Hipermídia para Aprendizagem. introduzir versões em língua estrangeira ou áudiodescrições detalhadas para os visitantes mais curiosos e interessados. (NEVES, 2006)

Na experiência, os visitantes utilizaram audioguias cedidos pelo próprio museu e as impressões e experiências de cada um serão relatadas a seguir.

\section{A proposta da aula passeio}

Este estudo teve início com a proposta da aula passeio oferecido pela professora de Metodologia Científica do CMPDI - UFF. O objetivo foi vivenciar uma experiência sensível no Museu do Amanhã que se articulassem com a diversidade e inclusão. O trabalho foi realizado em duplas e os autores responsáveis por esse estudo definiram como foco fazer um paralelo entre a experiência de um aluno vidente e um aluno cego.

\subsection{A primeira barreira: comunicação}

\begin{abstract}
O primeiro passo [...] é saber se o local dispõe de recursos de acessibilidade ou de educadores que possam fazer visitas monitoradas. É importante que o professor avise sobre a presença de alunos com deficiência, chamando a atenção do local para os recursos de acessibilidade que são um direito para uma participação em igualdade de condições. (MOTTA, 2016 pág. 163)
\end{abstract}

As tarefas do trabalho foram iniciadas com o envio de um e-mail para o endereço disponibilizado no fale Conosco do site do museu, solicitando o audioguia para o dia da visita. Esse e-mail nunca foi respondido. Outra aluna também enviou a solicitação, mas para um contato direto com a área de educação no museu (esse e-mail não está disponível no site, foi obtido através de contato pessoal) e conseguiu.
Um bom serviço de helpdesk poderá fazer a diferença entre o ganhar ou perder visitantes. Aqui se inscreve igualmente todo o material informativo que se fornece ao visitante in loco, ou a pedido. Aqui também serão incluídos todos os materiais criados especificamente para visitantes com necessidades especiais: as brochuras em Braille para cegos; os materiais ampliados ou em alto-contraste para amblíopes; os audioguias para cegos e amblíopes, estrangeiros, ou visitantes mais curiosos; e os materiais adaptados para crianças e para pessoas com dificuldades cognitivas ou mentais. (NEVES, 2006)

No dia da visita, a equipe da recepção não estava
Realização:

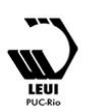




\section{$16^{\circ}$ \\ ERGODESIGN USIHC CINAHPA}

preparada para dar a devida informação sobre os audioguias. Foram entregues apenas cartões para interagir com o assistente digital IRIS, porém sem mais informações sobre o funcionamento do recurso. Não havia mapa nem programação impressa do museu.

O fornecimento de um mapa de visita à entrada, com uma composição gráfica clara e esclarecedora, auxiliará qualquer visitante a orientar-se no espaço e a conhecer a totalidade da exposição. Para que seja mesmo útil, este documento deverá estar em perfeito acordo com a exposição efectiva, evitando assim factores de desorientação. (NEVES, 2006)

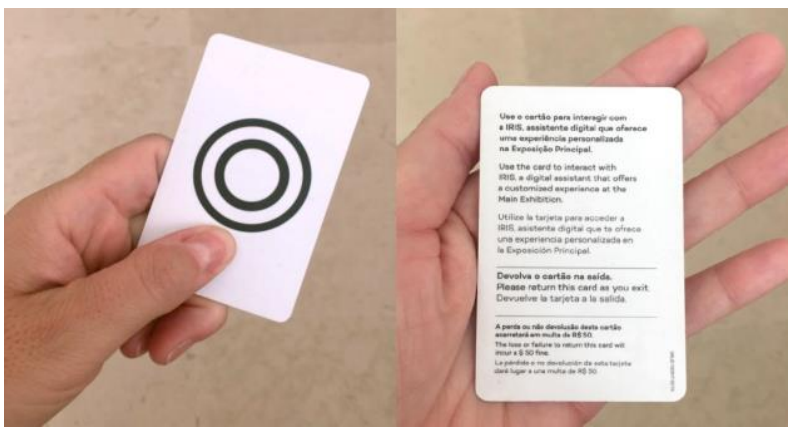

Figura 1: Cartão do assistente digital IRIS. Fonte: Da autora.

O dispositivo oferecido pelo museu é um tablet com uma proteção emborrachada e uma alça para ser pendurada no pescoço. Foi necessário algum tempo para se familiarizar com a navegação do audioguia, pois para o visitante cego, que utilizava o dispositivo pendurado no pescoço, os botões de navegação estavam disponibilizados no canto superior do tablet. Para o visitante que enxerga, ao levantar o tablet, esses botões passam a ser no canto inferior, que corresponde à informação disponibilizada no audioguia. A equipe não deu nenhuma informação sobre como navegar pelo conteúdo, com isso, não foi identificado onde começam as orientações.

\begin{abstract}
Tratando dos profissionais da Museologia, a necessidade de nova reflexão voltada às ações em Museus com relação à visitação e a comunicação que deste processo decorre ao recepcionar o segmento de público com deficiência, e neste particular, a de natureza visual. (BERQUÓ, 2011)
\end{abstract}

Só depois de ouvir alguns áudios foi possível entender que uns eram de orientação espacial e outros de descrição das obras. Não havia nenhum tipo de diferenciação sonora entre elas. $16^{\circ}$ Ergodesign - Congresso Internacional de Ergonomia e Usabilidade de Interfaces Humano Tecnológica: Produto, Informações Ambientes Construídos e Transporte

$16^{\circ}$ USIHC - Congresso Internacional de Ergonomia e Usabilidade de Interfaces Humano Computador

CINAHPA | 2017 - Congresso Internacional de Ambientes Hipermídia para Aprendizagem.

\subsection{Um passeio guiado pelo áudio}

Por falta de orientação, o acesso à exposição principal foi realizado sem o audioguia. Na saída do elevador havia um cordão interditando o acesso à frente, e o piso tátil direcional dava a opção de ir para a esquerda ou para a direita. Uma primeira observação feita pelo estudante cego é que a orientação do piso tátil é composta de apenas uma linha o que foge às normas da ABNT. Porém nesse estudo não será aprofundada a avaliação dos recursos táteis. O trajeto escolhido foi pela esquerda, onde encontra-se a primeira maquete tátil. A descrição foi localizada no audioguia, porém o estudante cego não conseguiu identificar pelo tato o que estava sendo dito em alguns pontos do áudio.

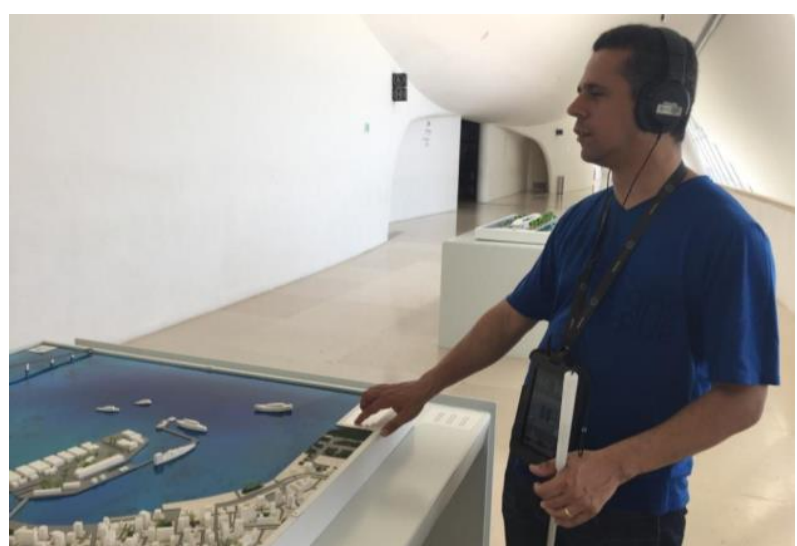

Figura 3: Aluno cego explora legenda em braille da maquete tátil. Fonte: Da autora.

Seguiu-se então para as demais maquetes. $\mathrm{Na}$ segunda maquete foi identificado um "ponto cego" no audioguia, pois, pelo recurso, orienta-se a utilizar o piso tátil para seguir para o próximo 


\section{$16^{\circ}$ \\ ERGODESIGN USIHC CINAHPA}

ponto. Nesse momento a aluna que enxerga solicitou ajuda aos monitores do museu. Nenhum deles estava preparado para orientar sobre a utilização do audioguia. Foi identificado, visualmente, que uma das maquetes tratava-se do que estava sendo exposto no outro lado do museu (trajeto que deveria ter sido tomado no começo da visita, na saída do elevador, pela direita). Se toda a equipe do museu (e não somente a de educação) tivesse as informações do audioguia, poderia ser evitada essa falha no guia.

\begin{abstract}
Acessibilidade: Do prédio às pessoas. O Museu do Amanhã tem a acessibilidade como premissa da construção física do prédio e, principalmente, da relação entre a equipe do
\end{abstract} Museu e seus visitantes. (MUSEU DO AMANHÃ, 2015)

O passeio foi reiniciado então, utilizando o trajeto da direita. $\mathrm{O}$ acesso porém teve que ser guiado pela aluna que enxerga, pois o piso tátil estava interditado com fitas.

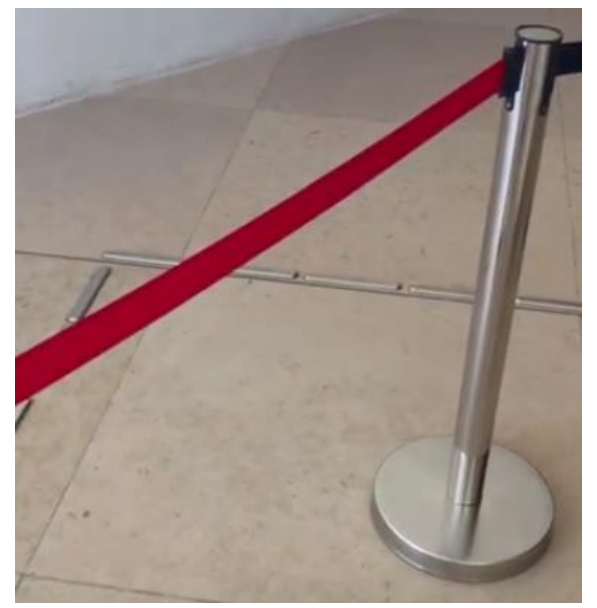

Figura 4: Piso tátil fora da área de acesso. Fonte: Da autora.

A exposição principal apresenta cinco grandes áreas: Cosmos, Terra, Antropoceno, Amanhãs e Nós. O Cosmos é um domo em formato de um ovo negro onde o visitante é imerso numa projeção em 360 graus, percorrendo galáxias, os átomos, o interior do Sol, a formação da Terra, o desenvolvimento da vida, do pensamento e da arte.

Um dos eixos éticos do Museu do Amanhã é o da convivência. Nossas experiências foram criadas para envolver a todos, sem distinção. Mas, para manter a qualidade da experiência, não disponibilizamos legendas na exibição do filme do Portal Cósmico. (MUSEU DO AMANHÃ̂, 2015) $16^{\circ}$ Ergodesign - Congresso Internacional de Ergonomia e Usabilidade de Interfaces Humano Tecnológica: Produto, Informações Ambientes Construídos e Transporte

$16^{\circ}$ USIHC - Congresso Internacional de Ergonomia e Usabilidade de Interfaces Humano Computador

CINAHPA | 2017 - Congresso Internacional de Ambientes Hipermídia para Aprendizagem.

Por se tratar de uma experiência multissensorial, algumas informações acabam se perdendo ao ser explorado somente o áudio como sentido. $\mathrm{O}$ dispositivo estava configurado para entrar em tela de descanso depois de um tempo. Com isso o áudio parava e, quando era retomado, já não estava sincronizado com os sons da projeção. Outro problema foi que, a cada transição de imagens, a áudio-descrição narra com a informação "a paisagem muda". Esse tipo de mensagem poderia ser substituída por mais detalhes da imagem que está sendo projetada no momento, seguindo as diretrizes básicas de uma áudio-descrição empoderativa.

O áudio-descritor deve respeitar as regras da boa áudiodescrição para incluir as informações visuais que sejam inacessíveis a pessoas cegas, ou com baixa visão, sem preencher cada pausa disponível. (AUDIODESCRIPTION COALITION, 2010)

Informar as mudanças de cena com relação a lugar e tempo; poucas palavras podem informar a mudança de cenário: no jardim, no escritório, dentro do quarto; e também com relação a mudança de tempo: é noite, é dia. (MOTTA, 2016 pág. 151)

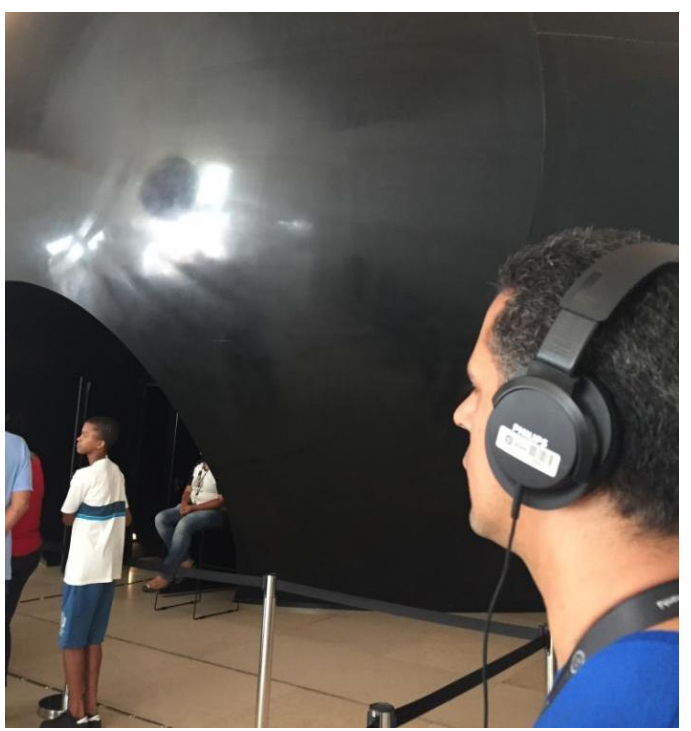

Figura 5 - Estudante cego em frente ao Espaço Cosmos. Fonte: Da autora.

Ao final da exploração do domo, foi necessário pular a faixa de orientação do audioguia e seguir para a faixa seguinte, pois a porta de saída estava interditada. No Portal Cósmico, mesas interativas apresentam com mais profundidade os aspectos e dimensões cósmicas. Não foi viável a exploração pelo estudante cego, pois a tela era sensível ao
Realização:
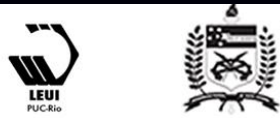


\section{$16^{\circ}$ \\ ERGODESIGN USIHC CINAHPA}

toque mas sem orientações espaciais áudiodescritas.

Toda a exposição narra uma história e dá-se a conhecer ao visitante ao longo de um percurso pensado para realçar elementos, estabelecer relações e criar sentidos. Por contingências do espaço ou das peças em disposição, criam-se caminhos a serem seguidos de forma mais ou menos estruturada para que o todo se mantenha coerente e ganhe significação. (NEVES, 2006)

Depois de se explorar o Universo, a segunda área do percurso apresenta a Terra: três grandes cubos que representam a "Matéria", "Vida" e "Pensamento". Em cada cubo, o lado de fora do espaço evidencia a unidade; do lado de dentro, explora-se a multiplicidade. Aqui pode ser destacado que o cubo "Vida" apresenta do lado de fora uma sequência das letras CTGA em baixo relevo. Fazendo um percurso tátil junto com a áudio-descrição, rapidamente o estudante cego pode perceber que tratava-se de sequências de DNA.

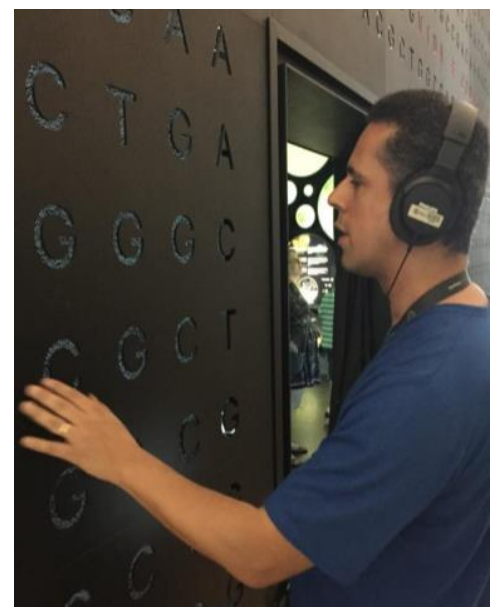

Figura 6: Estudante cego em frente ao cubo Vida. Fonte: Da autora.

No interior do cubo Matéria uma instalação apresentava um balé de tecidos que flutuavam por ação do vento. Ao bloquear algumas passagens do ar o tecido mudava o percurso. Tanto a estudante que enxerga quanto o estudante cego puderam perceber através dos sons, do tato (ao tocar as saídas de vento e o próprio tecido) e da áudiodescrição, os diferentes ritmos que marcam o funcionamento material do planeta, batizados de "oceanos".

Ler as imagens com os olhos e escutar a audiodescrição chama a atenção, desenvolve o senso de observação, $16^{\circ}$ Ergodesign - Congresso Internacional de Ergonomia e Usabilidade de Interfaces Humano Tecnológica: Produto, Informações Ambientes Construídos e Transporte

$16^{\circ}$ USIHC - Congresso Internacional de Ergonomia e Usabilidade de Interfaces Humano Computador

CINAHPA | 2017 - Congresso Internacional de Ambientes Hipermídia para Aprendizagem.

\begin{abstract}
destaca aquilo que não foi captado pela visão. Isso já tem sido comprovado por pessoas que enxergam e que assistem peças, óperas e filmes com audiodescrição. Ficam surpresas com o número de informações visuais que passariam despercebidas sem o recurso. (MOTTA, 2016 pág. 124)
\end{abstract}

Ao final de cada grande área, o audioguia dá a orientação direcional até a maquete. O problema é que a áudio-descrição é feita do final ao início da mesa onde estão as maquetes, fazendo com que o cego tenha que se dirigir ao final da maquete e voltar pelo percurso.

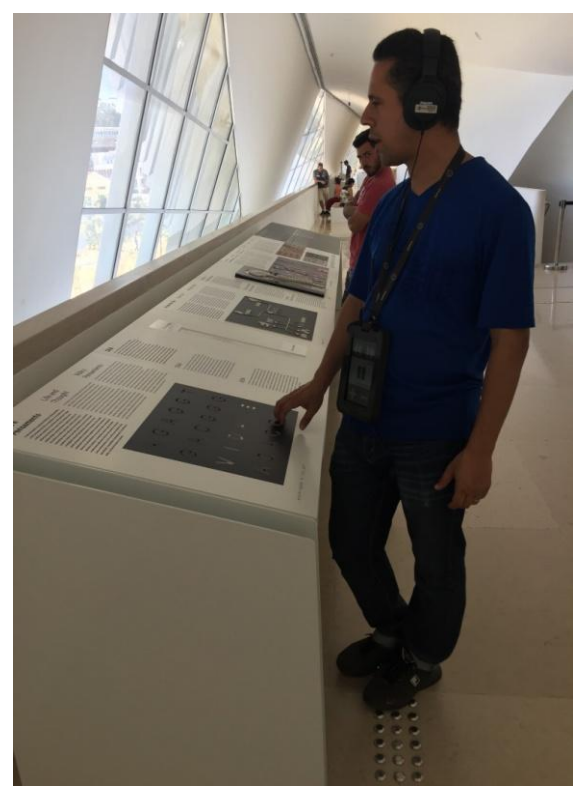

Figura 7: Estudante cego em frente a maquete tátil. Fonte: Da autora.

No último registro do estudo, a áudio-descrição de orientação para chegar no espaço Nós coloca a parede como linha de orientação. Ao final dessa linha não há nenhuma sinalização de alerta e a áudio-descrição não informa para qual lado devese prosseguir. Foi necessário que a estudante vidente orientasse o estudante cego a seguir para a esquerda para dar continuidade ao que estava sendo descrito, que era "tatear a oca".

O ambiente é inspirado em uma oca, "casa" de conhecimento indígena, onde os mais velhos contam aos mais jovens os conhecimentos que fundamentam a cultura. Seu elemento central é um churinga, objeto da cultura aborígene australiana que representa os conhecimentos passados adiante e é um elo entre gerações. É a única peça física presente na narrativa principal do Museu do Amanhã. (MUSEU DO AMANHÃ, 2015)
Realização:

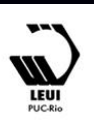




\section{$16^{\circ}$ \\ ERGODESIGN USIHC CINAHPA}

\section{Considerações finais}

De acordo com Berquó (2011), tornar um Museu 'inclusivo' implica a criação de programas e atividades que ofereçam a possibilidade das pessoas com deficiência e, neste caso, o deficiente visual participar ativamente, seja como consultor ou como orientador das melhores práticas.

Existe uma grande diferença de um Museu com práticas inclusivas e um Museu para todos. É louvável a iniciativa do Museu do Amanhã em suas práticas inclusivas, mas percebe-se que ainda existe um hiato entre a proposta de acessibilidade e a implantação efetiva dos recursos. A possibilidade de uma pesquisa futura envolve a avaliação qualitativa das áudio-descrições disponibilizadas no audioguia e a orientação da equipe de help-desk do museu que poderá resultar na elaboração de um checklist de adequações para melhor orientação e experiência do visitante cego.

\section{Referências Bibliográficas}

ABNT, Associação Brasileira de Normas Técnicas. Acessibilidade - Sinalização tátil no piso Diretrizes para elaboração de projetos e instalação. 2016. Disponível em

http://www.pessoacomdeficiencia.gov.br/app/sites/ default/files/arquivos/\%5Bfield_generico_imagens -filefield-description\%5D_168.pdf . Acesso em janeiro de 2017.

\section{AUDIO DESCRIPTION COALITION.}

Diretrizes para Áudio-Descrição e Código de Conduta Profissional para Áudio-descritores. Trad. de VIEIRA, P. Revista Brasileira de Tradução Visual, vol. 4, 2010. Disponível em http://www.associadosdainclusao.com.br/enades20 16/sites/all/themes/berry/documentos/12-uniaoem-prol-da-audio-descricao.pdf . Acesso em janeiro de 2017.

BERQUÓ, Ana Fátima; LIMA, Diana. F. C. Informação Especial no Museu-Acessibilidade: a inclusão social da pessoa com deficiência visual. Tendências da Pesquisa Brasileira em Ciência da Informação, v. 4, p. 1-20, 2011. $16^{\circ}$ Ergodesign - Congresso Internacional de Ergonomia e Usabilidade de Interfaces Humano Tecnológica: Produto, Informações Ambientes Construídos e Transporte

$16^{\circ}$ USIHC - Congresso Internacional de Ergonomia e Usabilidade de Interfaces Humano Computador

CINAHPA | 2017 - Congresso Internacional de Ambientes Hipermídia para Aprendizagem.
Disponível em

http://inseer.ibict.br/ancib/index.php/tpbci/article/d ownload/54/91 Acesso em janeiro de 2017.

LIMA, Francisco José; VIEIRA, Paulo André de Melo; RODRIGUES, Ediles Revorêdo e PASSOS, Simone São Marcos. Arte, educação e inclusão: orientações para áudio-descrição em museus. 2011. Disponível em http://www.associadosdainclusao.com.br/enades20 16/sites/all/themes/berry/documentos/10-arteeducacao-e-inclusao-orientacoes-para-audiodescricao-em-museus.pdf . Acesso em janeiro de 2017.

MOTTA, Lívia Maria Villela. A audiodescrição na escola: abrindo caminhos para leitura de mundo. São Paulo: Pontes, 2016.

RIO DE JANEIRO, Prefeitura Municipal. Museu do Amanhã: material de divulgação. 2015. Disponível em http://museudoamanha.org.br/sites/default/files/Md a BookConteudo jan2016.pdf . Acesso em janeiro de 2017.

NEVES, Josélia. Museus Acessíveis... museus para todos?! 2006. Disponível em: http://www.scribd.com/doc/17576420/NEVES200 6Museus- ${ }^{\circ}$ (C)- Para- ${ }^{\circ}$ C)- Todos\#open_download Acesso em janeiro de 2017.

SARTORETTO, M. L.; BERSCH, R. Assistiva tecnologia e educação. 2013. Disponível em: http://www.assistiva.com.br/tassistiva.html . Acesso em: janeiro de 2017.

SASSAKI, Romeu K. Inclusão da pessoa com deficiência no mercado de trabalho. São Paulo: Prodef, 1999. 